\title{
Fault slip-rate variations during crustal-scale strain localisation, central Italy
}

\author{
Gerald P. Roberts, ${ }^{1}$ Alessandro M. Michetti, ${ }^{2}$ Patience Cowie, ${ }^{3}$ Nigel C. Morewood, ${ }^{4}$ \\ and Ioannis Papanikolaou ${ }^{1}$
}

Received 24 May 2001; revised 12 December 2001; accepted 16 January 2002; published 17 April 2002.

[1] Rates of plate motion are generally uniform over $10-10^{2}$ Myrs timescales. Faults between tectonic plates might, therefore, be expected to show temporally-uniform slip-rates if the same number of faults remain active. For an extending region of the Eurasia-Africa plate boundary, Italy, finite throw values (vertical component of the slip) for seismogenic normal faults are less than that predicted when recent throw-rates are extrapolated over the fault lifetimes. The effect correlates with distance from the fault system tips and demonstrates that the slip-rates on centrally-located faults have increased with time. Neighbouring normal faults were active in the Quaternary but show no signs of surface faulting during the latest Pleistocene to Holocene. Death of these faults has provided the extra strain per unit time to drive the increased sliprates measured on other faults. Thus, fault interaction and death modify slip-rates and seismic hazards associated with plate tectonics. INDEX TERMS: 8150 Evolution of the Earth: Plate boundary-general (3040); 7230 Seismology: Seismicity and seismotectonics; 7221 Seismology: Paleoseismology

\section{Introduction}

[2] Faults with high slip-rates pose greater seismic hazards than neighbouring lower slip-rate faults. Thus, much time and effort has been spent mapping how fault slip-rates vary spatially, because such data are vital to understand the geography of seismic hazard [e.g. Galadini and Galli, 2000]. Less is known about how spatial patterns of slip-rate vary through time, yet fault systems evolve geometrically, often progressively localising the strain; it is this temporal variation in slip-rate and how it is related to localisation that is the subject of this paper.

[3] It is well known from studies of the growth of the Earth's ocean crust that tectonic plates move with rates that are generally uniform over tens to hundreds of millions of years [DeMets et al., 1994]. Where continental crust exists in the boundary zones between tectonic plates, relative plate motion is taken up mainly by slip on faults, accompanied by seismicity. The rates of deformation when summed across all the faults and related smaller structures including any distributed ductile strain will equal the rate of relative plate motion. If the rates of plate motion are uniform through time, then one would expect the summed rates of fault-slip to also be uniform through time if the same number of structures remain active. However, if the number of active structures decreases, localising

\footnotetext{
${ }^{1}$ The Research School of Geological \& Geophysical Sciences, Birkbeck College \& University College London, London, UK.

${ }^{2}$ Dipartimento di Scienze, Universita dell'Insubria, MM.FF.CC., Via Lucini, Como, Italia.

${ }^{3}$ Department of Geology and Geophysics, The University of Edinburgh, Edinburgh, UK.

${ }^{4}$ Department of Geology, University College Dublin, Belfield, Dublin 4, Ireland.
}

Copyright 2002 by the American Geophysical Union. 0094-8276/02/2001GL013529 the strainslip-rates increase on those that remain active [e.g. McLeod et al., 2000; Dawers and Underhill, 2000]. Surprisingly, we have no direct observations of deviations from present-day/recent slip-rates from active plate boundaries that can be linked with strain localisation, yet localisation will control the geography of seismic hazard. Some workers have shown that slip-rates on faults of different sizes appear to remain uniform through time [Nicol et al., 1997], whilst others suggest that slip-rates can fluctuate, or increase with time [Contreras et al., 2000; McLeod et al., 2000; Dawers and Underhill, 2000]. However, none of these studies are of active fault slip-rates measured in the Holocene. This is probably because such slip-rate data from active faults are usually thought to represent only a snapshot view of the motions. However, if the age of initiation of faulting is known, a relatively simple test of these constant, fluctuating or increasing slip-rate hypotheses is to compare measured finite slip values with slip-values implied when the present-day slip-rates are projected over the lifetime of the fault. If slip-rates remain constant through time then the resulting finite slip profiles will be identical to the predicted slip profiles.

\section{Regional Setting and Data Collection}

[4] The extending region of the Eurasia-Africa plate boundary zone in central Italy has been studied (Figures 1a and 1b). Here, continental crust is being deformed by large seismogenic normal faults running the length of the Italian peninsula. These faults are responsible for large magnitude, surface faulting earthquakes such as the 1915 Fucino Earthquake (Ms c. 7.0, surface rupture length $>23 \mathrm{~km}$ ) which caused 33,000 deaths. The threshold for surface faulting in the Apennines is about M 5.5 to 6 [Michetti et al., 1996, 2000]. Thus, we use the term active faults in this paper to indicate faults capable of producing surface faulting during strong earthquakes. We have measured both the finite throws (vertical component of slip) and throw-rates (vertical component of slip-rate) at a number of places along the faults, facilitating a comparison of profiles for these parameters (Figure 2). This is an unprecedented dataset from an active fault system on the Earth.

[5] Throw data have been collected during a 5 year field campaign where we mapped faults in the field and constructed serial cross-sections. The faults at the surface dip at high angles with a mean value of $65^{\circ}\left(\mathrm{N}=1653\right.$; Standard deviation $\left.=14^{\circ}\right)$. We have also utilised a large number of published geological maps which allow quantification of the senses and amounts of vertical offset of the stratigraphy across the faults [e.g. Vezzani and Ghisetti, 1998].

[6] Throw-rate data come from two sources. First, a large number of palaeoseismological trench site studies have been published for this region [e.g. Michetti et al., 1996; Pantosti et al., 1996; Galadini et al., 1997]. These have studied and dated offset Holocene deposits resulting in an extensive database of throw-rates averaged over relatively short time periods ( $<$ c. $5 \mathrm{kyrs})$. Second, the high topography of the area (up to c. $3000 \mathrm{~m}$ ) contained small mountain valley glaciers during the last glacial maximum. Extensive glacial and periglacial landforms, which are now faulted, date from this time. These deposits and landforms have been intensively studied and many published dates have been derived from radiocarbon, tephrachronological and stratigraphical correlation studies 


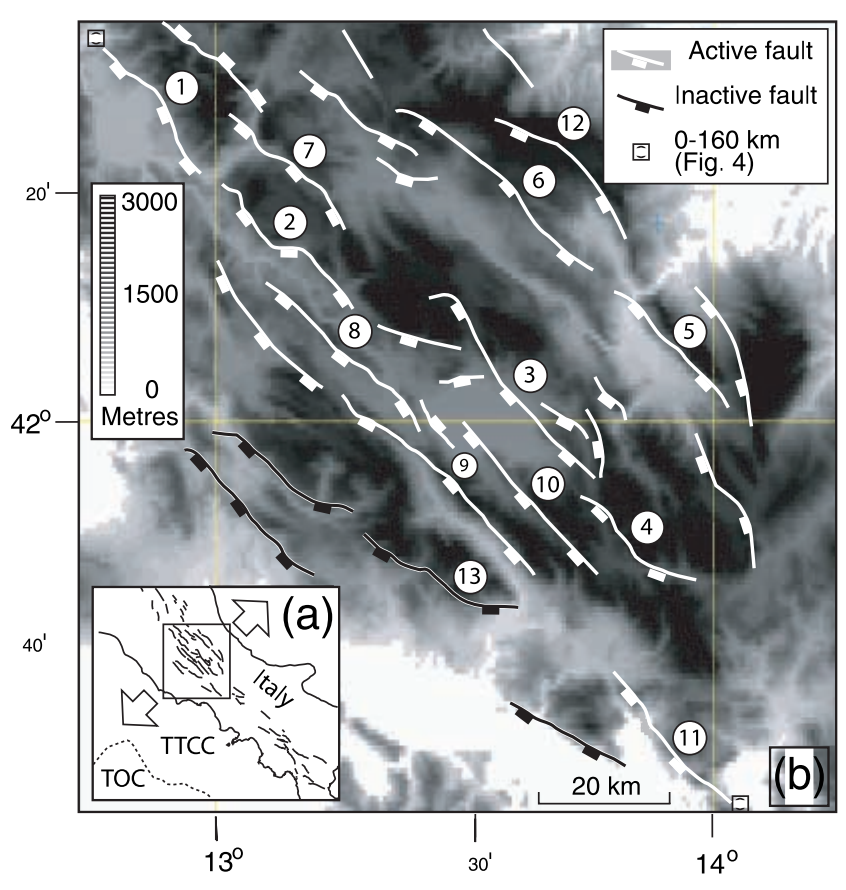

Figure 1. Location map (a), and fault map (b) for LazioAbruzzo, central Italy. Active normal faulting is confined to the zone of active faults shown running the length of the Italian Peninsula in (a). TOC - Tyrrhenian ocean crust; TTCC - Thinned Tyrrhenian continental crust.

with dated oceanic climate records [Giraudi and Frezzotti, 1987]. The demise of the last glaciation started at c. $18 \mathrm{ka}$. We measured the vertical offset of these landforms and deposits, to produce throwrate measurements averaged over the last $18 \mathrm{kyrs}$, a time period that is most-likely long enough to constrain the rate of slip over a number of seismic cycles. Where $5 \mathrm{ka}$ and $18 \mathrm{kyrs}$ data were collected at the same locality they show yielded very similar rates. These throw rates are shown on Figure 2 as throws that would develop over 3 Myrs, which we argue below is the likely age of initiation of extension in this area.

\section{Details of Fault Activity}

[7] We have found active and inactive faults whose activity partially overlapped in time allowing us to studt strain localisation through time. The active faults form a closely-spaced, soft-linked fault system with finite and Holocene/recent slip decreasing to zero at fault tips. These faults control Plio-Pleistocene-Recent hangingwall basins [Cavinato and De Celles, 1999], coincident with low topography areas on the digital elevation model, and have uplifted mountain ranges in their footwalls (Figure 1b). Across strike distances between active faults are only c. $7-15 \mathrm{~km}$ in places. However, in the southwest of the region, four faults show throws of several hundred metres or more, control the positions of PlioPleistocene hangingwall deposits and footwall mountain ranges, but show no signs of slip at surface in the upper Pleistocene or Holocene. The fault escarpments are well exposed, but no offset upper Pleistocene-Holocene deposits or bedrock scarps indicating post-glacial surface faulting have been found. No large magnitude historical or modern earthquakes (gt; Ms 5.5) are associated with these faults, and most workers agree that they do not have the potential for producing displacement at or near the surface [GNDT, 2000]. Despite the fact that on a large scale the locus of extension has migrated northeast, with a belt of now inactive Pliocene extensional basins located on the west coast of central Italy and Neogene ocean crust in the Tyrrhenian Sea (Figure 1a) [Jolivet et al., 1998; Cavinato and De Celles, 1999], periods of activity on the faults shown in Figure 1b overlap in time. The now inactive faults in the southwest control the positions of mid- to lower Pleistocene deposits containing famous elephant fossils (Elephas antiquus), as do presently-active faults in the northeast (e.g. Faults 1, 5, 6 and 13 Figure 1b). Lower Pleistocene Mammuthus (Archidiskodon) meridionalis vestinus have been found in the hangingwall basin to Fault 6 [Azzaroli et al., 1977; Esu et al., 1992]. The inactive faults were also active prior to the mid-lower Pleistocene because the deposits containing Elephas antiquus lie near the top of the hangingwall stratigraphic successions of these faults. The same is true also for the active faults, for instance, the Mammuthus bearing horizons in the hangingwall to Fault 6 overlie at least $200 \mathrm{~m}$ of older continental deposits. Moreover, this is supported by simple division of the finite throws by the throw-rates which implies the minimum time period over which the faults have been active assuming no change in throw-rates with time (Figure 3a). This implies that some of the presently-active faults have been active for up to about 3 Myrs, yet the presently inactive faults show no evidence of slip at the surface since about $0.5-0.9 \mathrm{Ma}$. There is no relationship between periods of activity implied by the above calculation and distance across strike along a northeast-southwest transect (Figure 3a). Thus, the evidence does not support a simple progressive eastward or northeastward migration of fault activity at a small scale within the area in Figure 1b. The presence of active and inactive faults whose activity partially overlapped in time shows that, in the area of Figure $1 b$, the number of active faults has decreased.

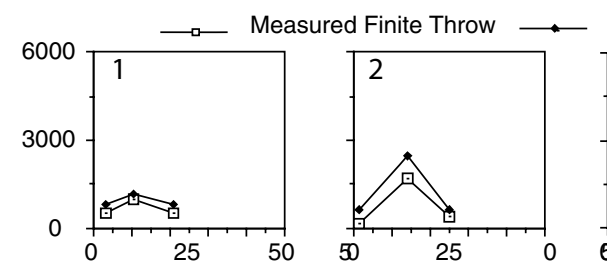

Predicted Throw (Throw rate in $\mathrm{mm} / \mathrm{yr} \times 3000$ )
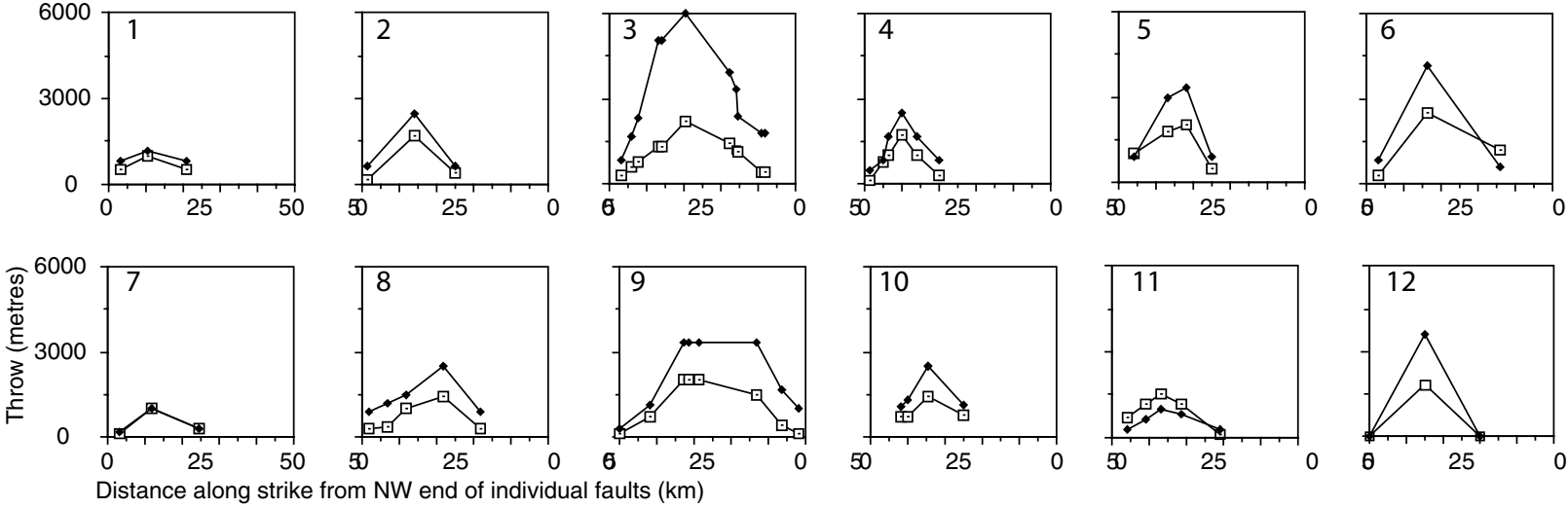

Figure 2. Throws and throw-rates (shown as the throw that would develop if the throw rates were extrapolated over 3 Myrs) versus distance data for active faults in central Italy. Numbers refer to the fault numbers in Figure 1. 

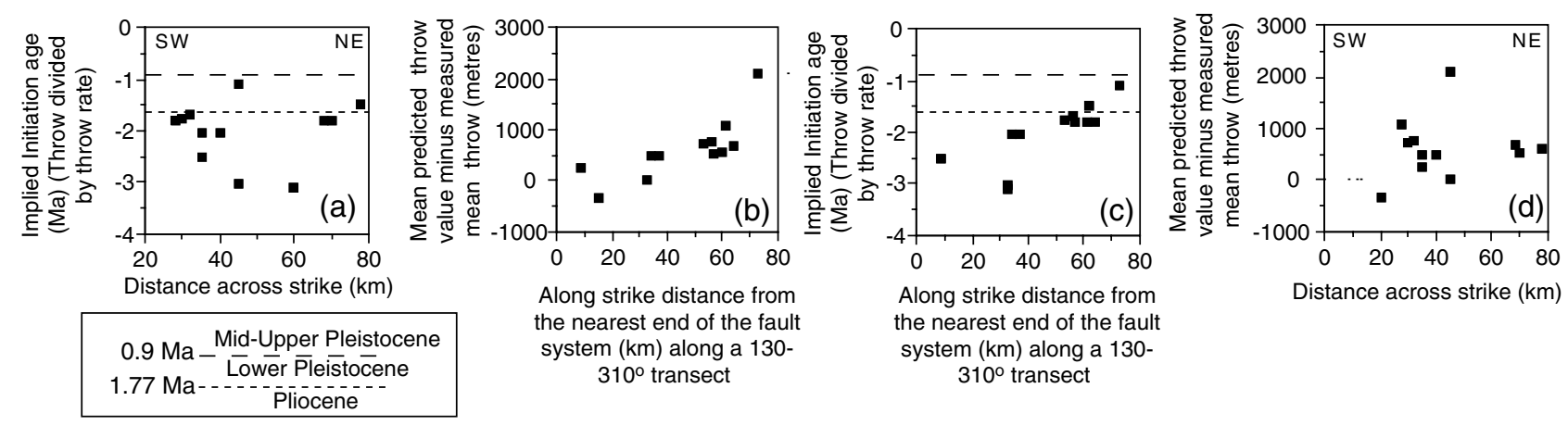

Figure 3. Graphs comparing implied initiation ages and mean differences between measured and predicted throws with distance across strike (a and d) and along strike (b and c). Pliocene-Pleistocene timescale from Shackleton [1997]. The method for predicting throws is given in the text.

[8] To investigate whether the rate of tectonic motion has slowed or the slip has been taken up elsewhere on other structures we can compare profiles of measured throw and predicted throw. We have projected the present-day throw-rates over 2, 3 and 4 Myrs (see Figure 2 for the 3 Myrs calculations) to predict what throws would have developed if throw-rates have remained constant over these time periods. The results show that predicted throw values are commonly larger than measured values. Thus, if the faults initiated synchronously, the present-day pattern of finite throws cannot have developed from the present-day pattern of throw-rates. Instead, it is implied that throw-rates have increased through time because constant throw-rates through time would produce identical measured throw and predicted throw profiles. Our results are insensitive to the initiation age we choose, because a similar pattern emerges if we use 2, 3 or 4 Myrs for the time of initiation. We favour an initiation age of about 3 Myrs for all the faults for reasons given later.

[9] For the 3 Myrs calculation, the data suggest that throw-rates have increased with time on all but one of the faults (Fault 11), with another showing no change (Fault 7), yet we know of no data which support an increase in the rate of far-field motion across this portion of the Africa-Eurasia plate boundary zone. If constant regional strain rates have been maintained, as seems likely, we suggest that the increased throw-rates have taken up the extra strain per unit time provided by switching-off of the four faults in the southwest of the region and the slowing of slip on Fault 11. Unfortunately, we cannot balance quantitatively the amounts of slip between faults that are suggested to be dead or dying faults and increased throw rate faults because we do not have data for all the active faults. The implied change in the slip distribution must have occurred $<0.9 \mathrm{Ma}$ constrained by the stratigraphic data mentioned above.

[10] The differences between predicted throws and measured throws is greater on faults located centrally along the strike of the fault system. We demonstrate this in 2 ways. First, we have calculated the difference between measured throws and predicted throws at individual localities; these have been used to calculate mean values for each fault. We have plotted these mean values as a function of distance from the ends of the fault system (Figure 3b). We have identified the ends of the fault system using our second technique. We have summed throws and throw-rates for the active faults along transects perpendicular to strike spaced every $5 \mathrm{~km}$ along the strike of the fault system (Figure 4). Summed throws and throw-rates (displayed as predicted throws for a 3 Myrs time period) are non-zero between the ends of the fault system, but close-to zero at these points. Notice that (1) a clear correlation exists between the difference between measured throw and predicted throw profiles for individual faults and distance from the ends of the fault system (Figure 3b), and (2) the summed profiles show a clear increase in the difference between measured throws and predicted throws towards the centre of the fault system (Figure 4). Thus, the increase in throw-rates with time is increasingly apparent towards the centre of the fault system when viewed along strike. Another way to interpret the above is that extension initiated earlier at the ends of the fault system (Figure 3c). However, we reject this interpretation and arguethat this correlation is simply the result of the increase in throw rates being most marked centrally along the strike of the fault system. Thus, the implied initiation ages are not actual initiation ages. They are simply the minimum age of initiation of faulting assuming no change in throw rates with time, when in fact the throw-rates have increased through time. Note that it cannot be that the throw-rates have slowed with time on the distal faults. This would have produced measured throws that are the same as predicted throws for central faults with a progressive decrease in predicted throws relative to measured throws with proximity to the ends of the fault system. Thus is the opposite of what we find.

[11] In fact we note that there is little difference between measured and predicted throws close to the ends of the fault system (Figures $3 b$ and 4 ). There is no evidence that these distal faults have experienced a significant change in throw rates. Thus,

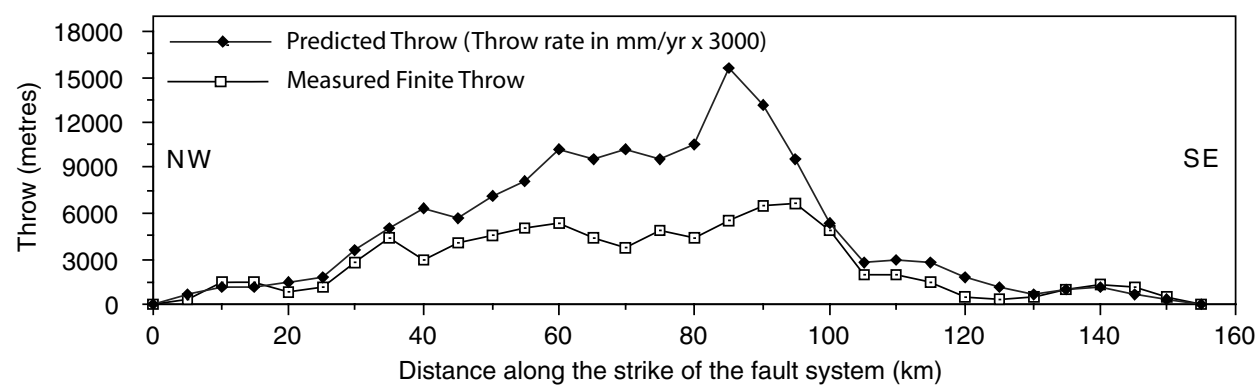

Figure 4. Measured and predicted throws summed across strike. The method for predicting throws is given in the text. The map-view end-points for the profile are shown in Figure 1. 
for distal faults the implied initation age (throw divided by throwrate) is probably a reasonable estimate of their actual initiation age. We note ages of about $3 \mathrm{Ma}$ (Figure 3c), explaining our choice of this value above. Finally, we note that no obvious relationship exists between levels of fault activity and distance across strike (Figure 3d) supporting our conclusion that their is no overall migration of faulting at a small-scale within the area of Figure 1b.

\section{Conclusions}

[12] When the faults in the southeast of the region decreased in activity localising the strain after about $0.9 \mathrm{Ma}$, the throw-rates on the remaining active faults increased with the effect most marked on faults located centrally along the strike of the fault system. The increase in throw-rates in the centre of an along-strike fault array accompanying death of other across strike faults is similar to that identified in fault growth models [Cowie, 1998; Cowie and Roberts, 2001] and studies of sub-surface seismic data of ancient fault movements [McLeod et al., 2000; Dawers and Underhill, 2000], but this is the first time it has been noted in a present-day deformation rate dataset from an active plate boundary zone. Our observations are consistent with the hypothesis that crustal scale strain localisation is accomplished by increasing slip-rates on faults that are to remain active whilst maintaining regional strain rates. Thus, fault slip-rates and their associated levels of seismic hazard are not simply controlled by the rates of plate tectonics; fault interaction also has a role to play.

[13] Acknowledgments. This work was funded by the Royal Society of London, NERC GR9/02995, Birkbeck College, and the State Scholarship Foundation of Greece (I.K.Y.). Athanassios Ganas helped make the digital elevation model. The Benfield Greig Hazard Research Centre at UCL is thanked for support.z

\section{References}

Azzaroli, B., et al., The Villafranchian stage in Italy and the Plio-Pleistocene boundary, G. Geol., 41, 61-79, 1977.

Cavinato, G. P., and P. G. De Celles, Extensional basins in the tectonically bimodal central Apennines fold-thrust belt, Italy: response to corner flow above a subducting slab in retrograde motion, Geology, 27, 955-958, 1999.

Contreras, J., M. H. Anders, and C. H. Scholz, Growth of a normal fault system: observations from the Lake Malawi basin of the east African rift, J. Struc. Geol., 22, 159-168, 2000.

Cowie, P. A., A healing-reloading feedback control on the growth rate of seismogenic faults, J. Struc. Geol., 20, 1075-1087, 1998.

Cowie, P. A., and G. P. Roberts, Constraining slip rates and spacings for active normal faults, J. Struc. Geol., 23, 1901-1915, 2001.

Dawers, N. H., and J. R. Underhill, The role of fault interaction and linkage in controlling syn-rift stratigraphic sequences: Stafjord East area, northern North Sea, A.A.P.G. Bull., 84, 45-64, 2000.
DeMets, C., R. G. Gordon, D. F. Argus, and S. Stein, Effect of recent revisions to the geomagnetic reversal timescale on estimates of current plate motions, Geophys. Res. Lett., 21, 2191-2194, 1994.

Esu, D., O. Girotti, and T. Kotsakis, Molluschi e vertebrati di alcuni bacini continentali dell'Appennino centrale: indicazioni biostratigrafiche e paleoecologiche, Studi Geologici Camerti, vol. spec. 1991/2, 295-299, 1992.

Galadini, F., P. Galli, and C. Giraudi, Geological investigations of Italian earthquakes: new paleoseismological data from the Fucino Plain (Central Italy), J. Geodynamics, 24, 87-103, 1997.

Galadini, F., and P. Galli, Active tectonics in the central Apennines (Italy) - Input data for seismic hazard assessment, Natural Hazards, 22, 225$270,2000$.

Giraudi, C., and M. Frezzotti, Late Pleistocene glacial events in the central Apennines, Italy, Quaternary Research, 48, 280-290, 1987.

GNDT, Gruppo Nazionale per la Difesa dai Terremoti. Sintesi delle conoscenze sulle faglie attivein Italia Centrale. M. Barchi, F. Galadini, G. Lavecchia, P. Messina, A. M. Michetti, L. Peruzza, A. Pizzi, E. Tondi and E. Vittori. Published by GNDT, Rome. ISBN 88-900449-7-7, pp 62, 2000 .

Jolivet, L., C. Facenna, B. Goffe, M. Mattei, F. Rossetti, C. Brunet, F Storti, R. Funiciello, J.-P. Cadet, N. d'Agostino, and T. Parra, Midcrustal shear zones in postorogenic extension: example from the northern Tyrrhenian Sea, J. Geoph. Res., 103, 12,123-12,160, 1998.

McLeod, A. E., N. H. Dawers, and J. R. Underhill, The propagation and linkage of normal faults: insights from the Strathspey-Brent-Statfjord fault array, northern North Sea, Basin Research, 12, 263-284, 2000.

Michetti, A. M., F. Brunamonte, L. Serva, and E. Vittori, Trench investigations of the 1915 Fucino earthquake fault scarps (Abruzzo, Central Italy): geological evidence of large historical events, J. Geoph. Res., 101, 5921-5936, 1996.

Michetti, A. M., L. Ferreli, E. Esposito, S. Porfido, A. M. Blumetti, E. Vittori, L. Serva, and G. P. Roberts, "Ground effects during the September 9, 1998, $\mathrm{Mw}=5.6$, Lauria earthquake and the seismic potential of the aseismic Pollino region in Southern Italy," Seis. Res. Letts., 71, 31-46, 2000.

Nicol, A., J. J. Walsh, J. Watterson, and J. Underhill, Displacement rates of normal faults, Nature, 390, 157-159, 1997.

Pantosti, D., G. D’Addezio, and F. Cinti, Paleoseismicity of the OvindoliPezza fault, central Apennines, Italy: a history including a large, previously unrecorded earthquake in the Middle Ages (860-1300 A.D.), J. Geoph. Res., 101, 5937-5960, 1996.

Shackleton, N. J., The deep-sea sediment record and the Pliocene-Pleistocene boundary, Quaternary International, 40, 33-35, 1997.

Vezzani, L., and F. Ghisetti, Carta Geologica Dell'Abruzzo, 1:100000, SELCA, Via R. Giuliani, 153 - Firenze, 1998.

G. P. Roberts and I. Papanikolaou, The Research School of Geological \& Geophysical Sciences, Birkbeck College \& University College London, Gower Street, London, UK.

A. M. Michetti, Dipartimento di Scienze, Universita dell'Insubria, MM.FF.CC., Via Lucini, Como, Italia.

P. Cowie, Department of Geology and Geophysics, The University of Edinburgh, West Mains Road, Edinburgh, UK

N. C. Morewood, Department of Geology, University College Dublin, Belfield, Dublin 4, Ireland. 